\title{
Three-dimensional finite element analysis of shallow indentation of rough strain-hardening surface
}

\author{
Chenghui GAO ${ }^{1}$, Henry PROUDHON ${ }^{2, *}$, Ming LIU ${ }^{1, *}$ \\ ${ }^{1}$ School of Mechanical Engineering and Automation, Fuzhou University, Fuzhou 350116, China \\ ${ }^{2}$ Centre des Matériaux, MINES Paris Tech, Evry Cedex 91003, France \\ Received: 09 November 2017 / Revised: 09 May 2018 / Accepted: 05 September 2018 \\ (C) The author(s) 2018. This article is published with open access at Springerlink.com
}

\begin{abstract}
Three-dimensional finite element modeling of the contact between a rigid spherical indenter and a rough surface is presented when considering both the loading and unloading phases. The relationships among the indentation load, displacement, contact area, and mean contact pressure for both loading and unloading are established through a curve fitting using sigmoid logistic and power law functions. The contact load is proportional to the contact area, and the mean contact pressure is related to the characteristic stress, which is dependent on the material properties. The residual displacement is proportional to the maximum indentation displacement. A proportional relationship also exists for plastically dissipated energy and work conducted during loading. The surface roughness results in an effective elastic modulus calculated from an initial unloading stiffness several times larger than the true value of elastic modulus. Nonetheless, the calculated modulus under a shallow spherical indentation can still be applied for a relative comparison.
\end{abstract}

Keywords: finite element modeling; surface analysis; contact mechanics; indentation; spherical indenter

\section{Introduction}

There has been a plethora of research on the surface roughness and its dependence on the machining parameters [1,2] owing to its influence on the contact heat transfer [3], wear [4], adhesion, stiction, electrical conductivity of the interface, and surface functions (e.g., coating performance, frictional behavior, and fluid load capacity [5]), and because it plays a key role in the physical properties of micro/nano structures. Adhesion between particles and surfaces, which is closely associated with various technological processes (e.g., pharmaceutical processes and powder painting), depends on the surface roughness because it reduces the true contact area leading to reduced body interaction [6]. Surface roughness also plays a significant role in the dispersion forces, which can generate severe problems such as spontaneous stiction or permanent adhesion between separate elements (e.g., suspended structures with a very small gap distance) in micro-electromechanical systems [7]. Lyon et al. [8] theoretically studied the effects of roughness at the atomic scale on the surface plasmon excitation, and found visible effects of the surface roughness on the image potential and stopping power. Through a molecular dynamics simulation, Liu et al. [9] found that the surface roughness plays a significant role in the plasticity initiation of silicon nanowires. Nunez and Polycarpou [10] experimentally investigated the effects of the counterpart surface roughness on the formation of a transfer layer from the polymer films for application to dry or solid lubrication, and determined the dependence of the friction coefficient and wear rate on the surface roughness. Zhu et al. [11] studied the influence of the surface roughness on wheel-rail adhesion and wear through the use of a rollingsliding tribometer. They found that increasing the surface roughness will increase the wear, and that the

* Corresponding authors: Henry PROUDHON, E-mail: henry.proudhon@mines-paristech.fr; Ming LIU, E-mail: mingliu@fzu.edu.cn 
surface roughness influences the adhesion recovery. Dawood et al. [12] studied the effects of the surface roughness during the friction stir welding of 6061 aluminum alloy workpieces. They found perceptible influences of the surface roughness of a workpiece on the quality of the weld surface, as well as the heat flux, grain refinement, tensile properties, micro-hardness, and fracture of the joints. Curry et al. [13] found that the structure, failure, and thermal conductivity of a columnar coating generated by suspension plasma spaying are strongly influenced by the topography of the surface onto which the coating is deposited.

The important effects of the surface roughness have motivated extensive studies on the contact between the rough surfaces of fractal or sinusoidal features [14-19] (e.g., frictionless normal contact between rough surfaces [20], elastic frictionless non-adhesive contact between rough surfaces [21-23], plastic deformation of rough rolling contact [24], contact stiffnesses of rough surfaces [25], and plastic contact with/without strain hardening [26-28]). Greenwood and Williamson [29] assumed a Gaussian distribution in the heights of spherical asperities through the application of Hertz theory [30] to each asperity. In addition, variations in radius, height, and ellipticity were considered by Bush et al. [31]. A scaling approach was used by Persson [32] as a way to consider the roughness of successive length scales owing to the self-affine fractal characteristic of the surfaces. Because the contact pressure is often sufficiently high to induce plastic deformation, statistical models considering elastic-plastic asperities have also been developed [33-35]. These theoretical models ignore the interaction between neighboring asperities as well as the bulk deformation of the base material, however, and suffer from many shortcomings (e.g., a discontinuous elastic-plastic transition [34]). Because the actual surface topography, interactions among asperities, and the plasticity can be considered, the finite element method is a deterministic approach to investigating the elastic-plastic contact of rough surfaces. Pei et al. [36] adopted a fully three-dimensional (3D) finite element (FE) modeling for contact of an elastic-plastic rough surface and a rigid flat surface, and found that the results for elastic-plastic solids were in contrast to previous studies on elastic solids [37]. Poulios and Kilt [38] studied the frictionless contact of nominally flat rough surfaces by applying a 3D FE model with a real surface topography and elasticplastic material behavior. Dong and Cao [39] simulated the deformation behavior of the elastic-linear plastic asperity of a sinusoidal profile using a 3D FE model, and correlated the subsurface stress conditions with a fatigue layer. Liu et al. [40] studied the normal contact of elastic asperities with an elliptical contact area, and investigated the effects of the geometrical and material parameters on contact stiffness. This work is devoted to addressing the contact mechanism of a rough surface through the finite element modeling of a spherical indentation of an experimentally measured rough surface. The contact variables (e.g., normal load and contact area) are quantified, and explicit relations are presented based on the simulation results.

\section{Finite element modeling of rough surface contact}

The material used herein is gold, and the surface topography is extracted from atomic force microscopy (AFM). Figure 1 shows an AFM image of a gold (a)

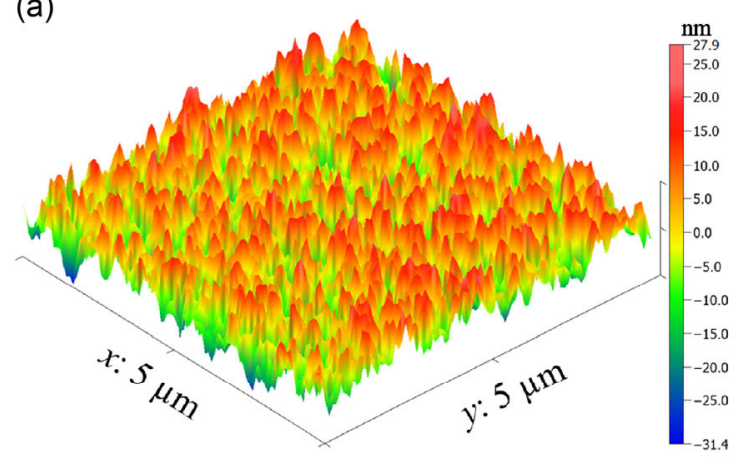

(b)

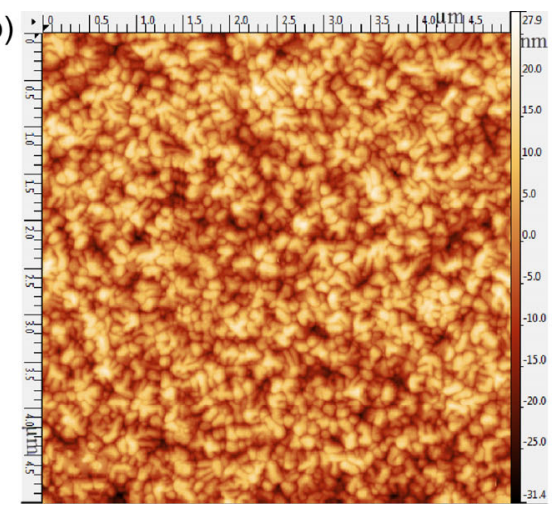

Fig. 1 AFM image of surface topography (size $5 \mu \mathrm{m} \times 5 \mu \mathrm{m}$ ): (a) three-dimensional and (b) projected views. 
surface with a scan size $5 \mu \mathrm{m} \times 5 \mu \mathrm{m}$, data array of $512 \times 512$, and surface resolution $\Delta=9.8 \mathrm{~nm}$, which is sufficient for modeling the contact behavior because a high resolution of about tens of nanometers is required to properly represent the surface topography [41]. The data are visualized and analyzed using Gwyddion 2.41: the arithmetical mean deviation $R_{\mathrm{a}} \approx 6.71 \mathrm{~nm}$, the root-mean-square (rms) roughness $R_{\mathrm{q}} \approx 8.21 \mathrm{~nm}$, the skewness $R_{\mathrm{sk}}=-0.0285$, the kurtosis $R_{\mathrm{ku}}=-0.436$; and the rms slope $\left\langle|\partial z / \partial x|^{2}\right\rangle=0.94$ (the brackets indicate the average of all values, where $z$ is the surface height). The average peak-to-valley and curvature radius of the asperities are $35 \mathrm{~nm}$ and $240 \mathrm{~nm}$, respectively [42].

The one-dimensional height-height correlation function in this study is defined as

$$
H_{x}\left(\tau_{x}\right)=\frac{1}{N(M-m)} \sum_{l=1}^{N} \sum_{n=1}^{M-m}\left(z_{n+m, l}-z_{n, l}\right)^{2}
$$

where $N=M=512$ (the same as a data array of $512 \times$ 512 for the AFM scan), and $\tau_{x}$ is the distance from point $(n+m, l)$ to point $(n, l)$. As expected, $H_{x}\left(\tau_{x}\right)$ is proportional to $\tau_{x}^{2 H}$ ( $H$ is the Hurst or roughness exponent) when $\tau_{x}$ is smaller than the lateral length $\left(\approx 10 R_{q}\right.$ for the case shown in Fig. 2(a)), and $H_{x}\left(\tau_{x}\right)$ reaches $2 R_{q}{ }^{2}$ when $\tau_{x}$ is larger than the lateral correlation length $\xi\left(\left(\xi \approx 60 R_{q}\right)\right.$ in Fig. 2). Figure 2 is obtained by analyzing the experimentally measured surface data with Eq. (1). As expected, $0<H<1$, and our result, $H=0.77$, for the case shown in Fig. 2 are in line with typical experimental values of $H$, namely, $0.5 \leq H \leq 0.8$ [43-45]. In addition, $2 H=4-2 D$ (where $D$ is the fractal dimension of the surface profile), and $D=1.23$ in line

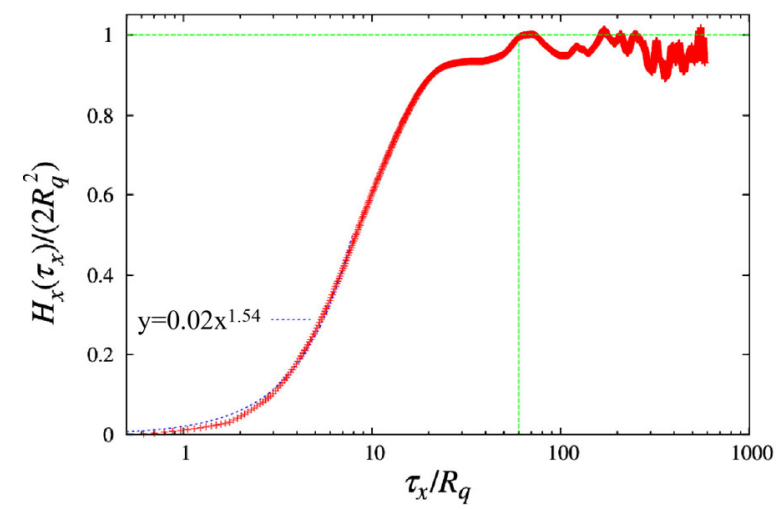

Fig. 2 One-dimensional height-height correlation function extracted from the image. with the reasonable range of $1<D<2$ [46].

Figure 3 shows a 3D FE mesh with half a million nodes for the sample to be indented. A fine mesh is used on the top surface, and the mesh becomes increasingly coarser away from the surface. The 3D FE simulation is carried out using the finite element package Z-set, applying its parallel solver [47-49]. The FE mesh is constructed using the AFM data shown in Fig. 1. The in-plane dimensions are $2.5 \mu \mathrm{m} \times 2.5 \mu \mathrm{m}$ because only the central region of the scanned image is used for generating a rough surface in finite element modeling. The thickness of the indented sample is about $2.5 \mu \mathrm{m}$, which is sufficiently high to represent a bulk material deformation under the displacements considered $(\leq 20 \mathrm{~nm})$. The smallest element at the surface of the mesh is $9.8 \mathrm{~nm}$, which is the same as the surface resolution in an AFM scan. Linear elements are used because they were found to be more accurate owing to a greater consistency in terms of the lumped mass matrix [50], although Mesarovic and Fleck [51] found that second-order elements show better convergence and accuracy than linear elements. The shapes of the nano-scaled asperities cannot be determined because the radii of the AFM tip and peaks are comparable. A 3D finite element mesh with a rough surface is generated from a 3D finite element mesh with a flat surface. Each node on the top surface corresponds to one measurement in the AFM map, and the surface roughness is generated by displacing each node on the surface in the direction normal to the top surface based on the height from this map. The finite element model consists of approximately half a million nodes. The contact area predicted by the finite element method is closely related to the number of nodes in contact, and thus depends strongly on the finite element mesh [48]. A reasonable mesh convergence requires 32 elements to describe the shape of one single asperity [48]. However, the difference between various meshes is

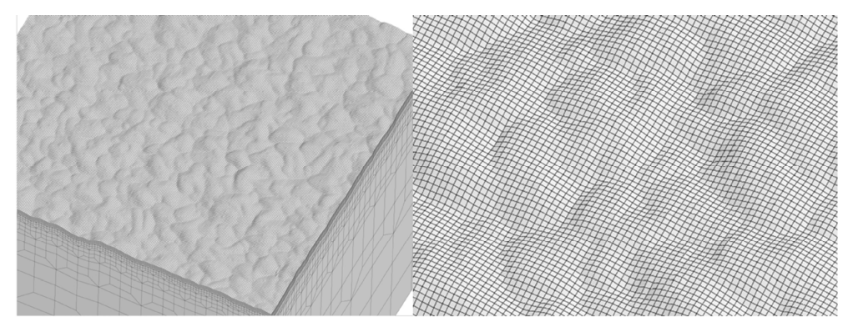

Fig. 3 3D FE mesh (dimensions: $2.5 \mu \mathrm{m} \times 2.5 \mu \mathrm{m} \times 2.5 \mu \mathrm{m}$; surface resolution $\boldsymbol{\Delta}=9.8 \mathrm{~nm}$ ). 
more sensitive when the displacements or forces are small [48]. The force is overestimated by a few percentages for the present mesh density compared with a denser mesh with an element size half of the present size. The present mesh is used for computational efficiency. To ensure good precision, the increment of the contact interference is set to $1 \mathrm{~nm}$. A rigid spherical indenter with a radius of $50 \mu \mathrm{m}$ is fixed above the center of the indented surface. The sample is brought into contact with the indenter by applying a uniform displacement on the bottom surface of the sample. Zero in-plane displacements are applied to the bottom surface. The symmetric boundary conditions are applied to the lateral faces. In the initial state, the highest point of the rough indented surface and the lowest point of the spherical indenter both have the same coordinate of $z=0$, and no contact occurs between the indenter and sample.

A frictionless (i.e., perfectly slip) contact condition, which corresponds to a fully lubricated contact condition in a real experiment, is typically adopted in a contact analysis [51-58] because no discernable differences between frictionless and frictional contacts have been found [59] in spite of the difference in the stress field near the contact surface [60] between a frictionless contact and a fully stick contact [61]. The classical non-penetration/non-adhesion contact condition with a rigid surface is used in the following form [62]:

$$
\sigma_{\mathrm{n}} g_{\mathrm{n}}=0, \sigma_{\mathrm{n}} \leq 0, g_{\mathrm{n}} \geq 0, \sigma_{\mathrm{t}}=0
$$

where $\sigma_{\mathrm{n}}=\mathbf{n} \cdot \sigma \cdot \mathbf{n}$ is the normal stress on the contact surface, $g_{\mathrm{n}}$ is the normal gap between the deformable solid and the rigid plane, and $\sigma_{\mathrm{t}}$ is the tangential stress. The contact algorithm enforces an impenetrability constraint on the contact surfaces.

Strain hardening is considered because very few materials exhibit an elastic-perfectly plastic behavior [63]. Isotropic rate-independent $J_{2}$ plasticity is used for the constitutive equation,

$$
\bar{\sigma}=\sqrt{\frac{3 s_{i j} s_{i j}}{2}}=\sigma_{\mathrm{y}}+K \alpha
$$

where $s_{i j}$ is the deviatoric part of the stress tensor, $\bar{\sigma}$ is the effective Mises stress, and $\alpha$ is an internal hardening variable. Because a generalized solution applicable to all types of materials has yet to be developed [64], and the contact responses differ from one hardening law to another [51], three different strain hardening laws are considered: linear, exponential, and power hardening:

$$
\alpha= \begin{cases}\varepsilon_{\mathrm{p}}=\int_{0}^{t} \dot{\varepsilon}_{\mathrm{p}}: \dot{\varepsilon}_{\mathrm{p}} \mathrm{d} t, & \text { linear; } \\ 1-\exp \left(-b \dot{\varepsilon}_{\mathrm{p}}\right), & \text { exponential; } \\ \varepsilon_{\mathrm{p}}^{n}, & \text { power }\end{cases}
$$

where $\varepsilon_{\mathrm{p}}$ and $\dot{\varepsilon}_{\mathrm{p}}$ are respectively the effective plastic strain and effective plastic strain rate

$$
\dot{\varepsilon}_{\mathrm{p}}=\sqrt{\frac{2}{3} \dot{\varepsilon}_{i j} \dot{\varepsilon}_{i j}}
$$

where $\dot{\varepsilon}_{i j}$ is the plastic strain rate tensor.

The material properties are listed in Table 1 . The material used for the linear strain-hardening law is gold $(\mathrm{Au})$ owing to its linear relationship between load and reduction area, and the similarity between the load-reduction area and stress-strain curves. Linear strain hardening is expressed in terms of the tangent modulus, which is the slope of the uni-axial stressstrain curve beyond the elastic limit. The poisson's ratio of $\mathrm{Au}$ is from [41] and [65]. Two different sets of material parameters are used for linear strain hardening: Au-1 with a small strain hardening, and Au-2 with a large strain hardening, which is beneficial in reducing the friction and wear [66] from a larger stiffness. The tangent modulus $K=1.07 \mathrm{GPa}$ for Au- 1 is less than $0.02 E$, which is the upper limit of many practical materials $[67,68]$, and $\mathrm{Au}-1$ can be considered an elastic-perfectly plastic material because isotropic linear hardening renders the same results as elasticperfectly plastic behavior [69], and a tangential modulus of up to $10 \%$ of the elastic modulus has only a small effect on the frictionless and non-adhesive contact [70]. The material used for the exponential hardening law is

Table 1 Mechanical properties of elastic-plastic materials.

\begin{tabular}{cccccc}
\hline Materials & $E(\mathrm{GPa})$ & $v$ & $\sigma_{\mathrm{y}}(\mathrm{GPa})$ & $K(\mathrm{GPa})$ & \\
\hline $\mathrm{Au}-1$ & 60 & 0.42 & 0.33 & 1.07 & \\
$\mathrm{Au}-2$ & 80 & 0.42 & 0.3 & 10 & \\
$\mathrm{Fe}$ & 175 & 0.3 & 0.44 & 0.49 & $b=242$ \\
$\mathrm{Cu}$ & 122 & 0.33 & 0.24 & 0.34 & $n=0.57$ \\
\hline
\end{tabular}


a hard-facing steel specimen ( $\mathrm{Fe}$ ) showing satisfactory agreement between the numerical and experimental results [48]. The elastic modulus and poisson's ratio for Fe are from[71]. The material used for the power hardening material is copper, the properties of which are from [58].

\section{Results and discussion}

Uncertainty exists in the first contact point, and there is difficulty in capturing the first contact. The first appearance of a detectable contact area is regarded as corresponding to zero indentation displacement $(h=0)$. The indentation displacement is the displacement of the bottom surface of the bulk sample minus this initial displacement corresponding to the smallest detectable reaction force. Only the loading process has been
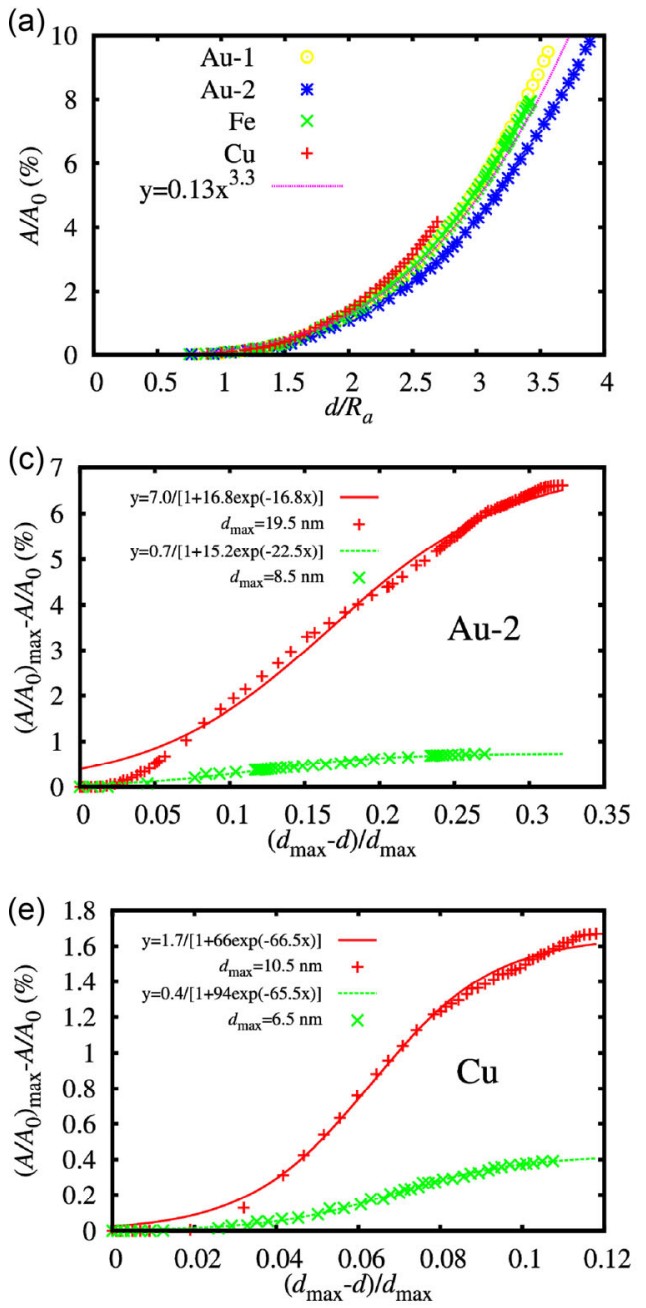

previously studied [48, 72-74]. Both loading and unloading are considered in the present work, similar to the analysis of the indentation cycle in [26].

\subsection{Relation between contact area and indentation displacement}

Figure 4(a) shows the variation in the real contact area $A$ normalized by the base area $\left(A_{0}=6.25 \mu \mathrm{m}^{2}\right)$ with indentation displacement $d$ normalized by $R_{a}$ during loading. The material properties have an effect on the morphologies of the contact regions during contact. Different materials produce qualitatively different behaviors in the distributions of the local contact pressures and sizes of the connected contact regions, which is consistent with previous findings [36]. Statistical fluctuations are important for a small amount of contact (i.e., the total number of nodes in
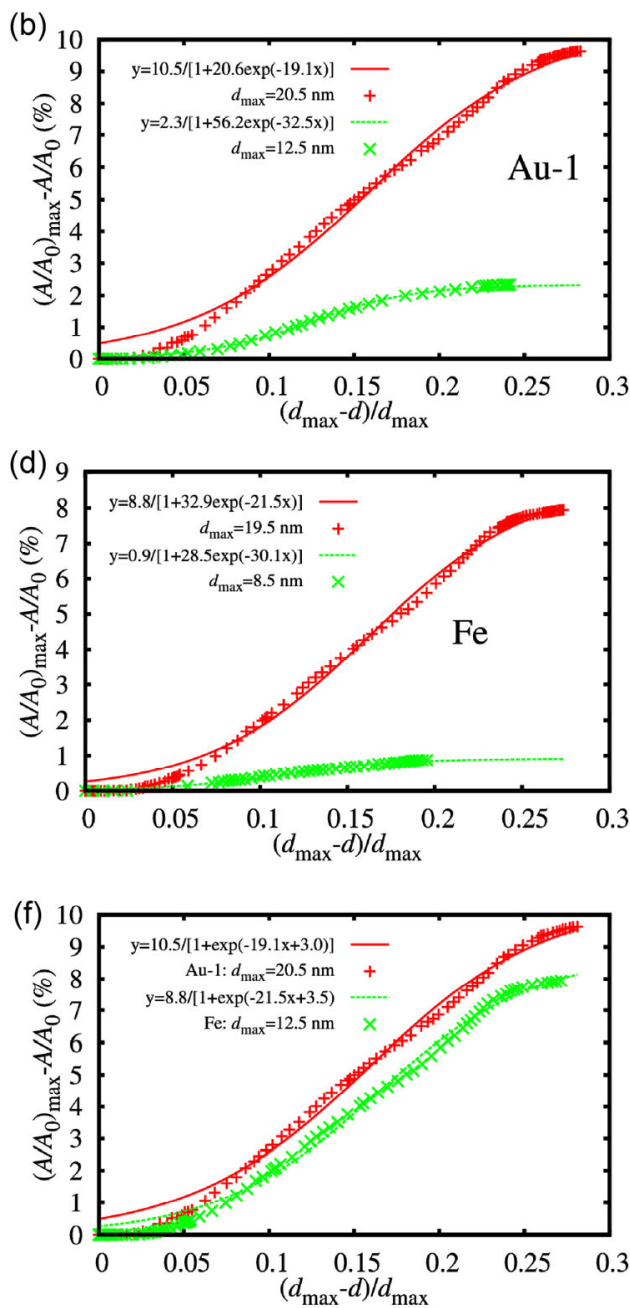

Fig. 4 Dependence of contact area on indentation displacement: (a) loading for four materials; (b) unloading for Au-1; (c) unloading for $\mathrm{Au}-2$; (d) unloading for Fe; (e) unloading for $\mathrm{Cu}$; and (f) unloading for Au-1 and Fe with a different type of fitting function. 
contact with each other is quite small), and the area is strongly dependent on the specific realization of the random surface $[36,37]$ as well as the specific material properties. A power function can be used to express the relation between the contact area and indentation displacement, namely, $A=D_{1} d^{D_{2}}$, with parameters $D_{1}$ and $D_{2}$ being dependent on the material properties. A difference in the $A-d$ curves for different materials occurs because the plasticity can affect the distribution of the contact area [36].

The unloading $A$ versus $d$ curves for different materials can be expressed using a sigmoid logistic type function (see Figs. 4(b)-4(e)):

$$
\left(\frac{A}{A_{0}}\right)_{\max }-\frac{A}{A_{0}}=\frac{D_{3}}{1+D_{4} \exp \left[-D_{5}\left(\frac{d_{\max }-d}{d_{\max }}\right)\right]}
$$
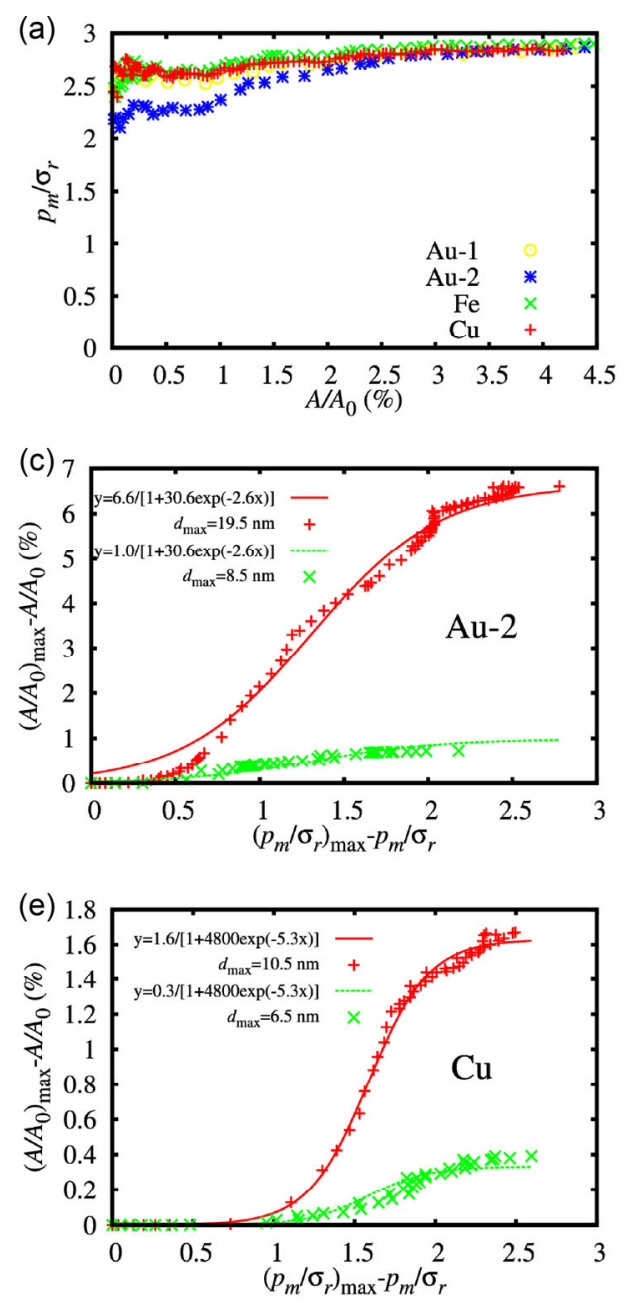

where the subscript "max" indicates the value at the final loading (i.e., the maximum indentation displacement, $\left.d_{\max }\right)$, and $D_{3}, D_{4}$, and $D_{5}$ are dependent on both the material properties and $d_{\max }$. At the initial stage of unloading $\left(d>0.98 d_{\max }\right)$, the contact area remains unchanged with a decrease in the indentation displacement. The presence of residual indentation displacement at the final unloading is due to the occurrence of plastic deformation. Other types of sigmoid logistic functions are also applicable for the unloading curve fitting (see the example in Fig. 4(f)).

\subsection{Relation between mean contact pressure and contact area}

Figure 5(a) shows the variation in the mean contact pressure $p_{\mathrm{m}}=F / A$ (where $F$ is a normal load) with $A / A_{0}$ during loading. In addition, $p_{\mathrm{m}}$ is normalized
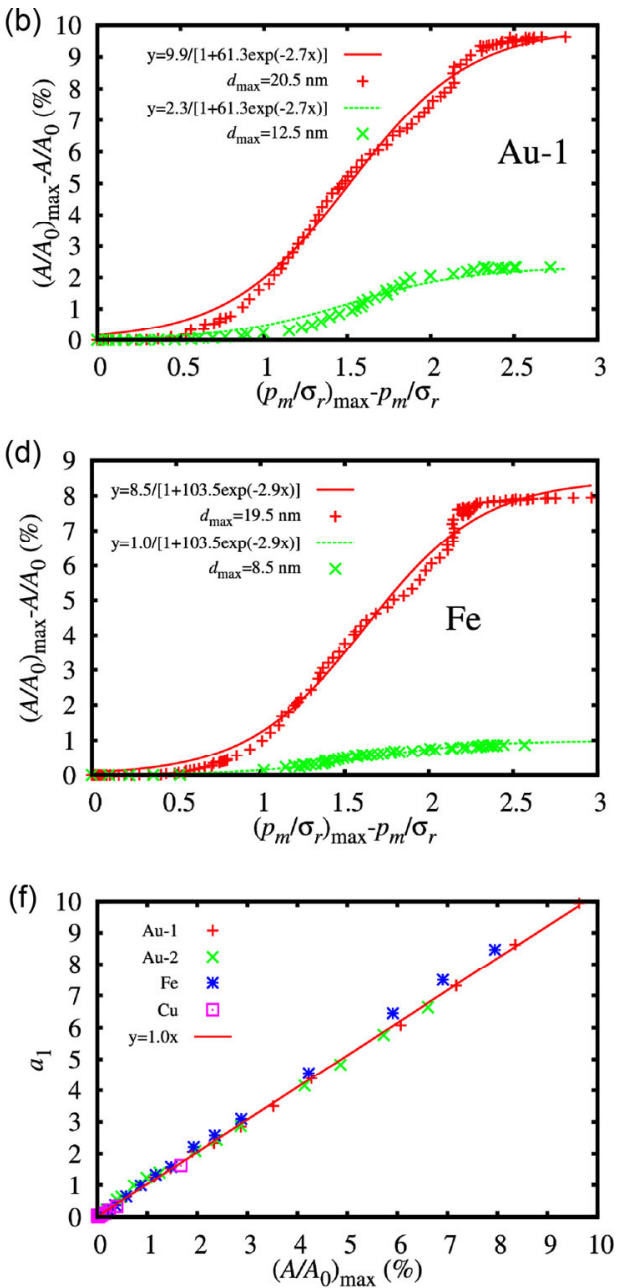

Fig. 5 Dependence of mean contact pressure on contact area: (a) loading for four materials; (b) unloading for Au-1; (c) unloading for $\mathrm{Au}-2$; (d) unloading for $\mathrm{Fe}$; (e) unloading for $\mathrm{Cu}$; and (f) relation between $a_{1}$ and $\left(A / A_{0}\right)_{\max }$. 
based on the characteristic stress, $\sigma_{\mathrm{r}}$ :

$$
\sigma_{\mathrm{r}}= \begin{cases}\sigma_{\mathrm{y}}+K \varepsilon_{\mathrm{r}}, & \text { linear; } \\ \sigma_{\mathrm{y}}+K, & \text { exponential; } \\ \sigma_{\mathrm{y}}+K \varepsilon_{\mathrm{r}}^{n}, & \text { power }\end{cases}
$$

where $\varepsilon_{\mathrm{r}}$ is the characteristic strain, and $\varepsilon_{\mathrm{r}}=0.1$ for $\mathrm{Au}-1, \varepsilon_{\mathrm{r}}=0.05$ for $\mathrm{Au}-2$, and $\varepsilon_{\mathrm{r}}=0.17$ for $\mathrm{Cu}$. In addition, $\sigma_{\mathrm{r}}$ for $\mathrm{Au}-2$ is higher than that for $\mathrm{Au}-1$ because Au-2 is stiffer owing to a larger tangent plasticity modulus, which is consistent with a larger contact pressure for a stiffer material [66]. The criterion used for choosing the characteristic strains for different materials is that, under a large contact area, the normalized stresses for different materials become almost the same, as shown in Fig. 5(a). A material with exponential strain hardening is used as a reference because it has no characteristic strain. Changing the strain-hardening rate is an effective way to modify the deformation resistance capability of a material under elastic-plastic deformation, and the characteristic stress is an imprint of the material stiffness.

As expected, the mean contact pressure is sufficiently large to produce plastic deformation [36]. If asperities constituting a rough surface are approximated using sinusoidal shapes, the aspect ratio (i.e., the ratio of height to width) is about 0.05 for most asperities [48]. Under such a small aspect ratio (i.e., short-wide type), the plastic strain reaches a stable platform for contact of an isolated asperity [39]. The plateau of the mean contact pressure for contact of a rough surface is in line with the plateau of the contact stress and the plastic strain on the peak of each individual asperity [39]. For a material with small strain hardening ( $\mathrm{Au}-1, \mathrm{Fe}$, and $\mathrm{Cu}$ ), the contact pressure reaches approximately 3 times the characteristic stress very quickly after initial contact occurs, and a plateau of the mean contact pressure can be approximated during loading. For a material with large strain hardening (Au-2), $p_{\mathrm{m}}$ increases gradually during the initial stage of contact, and approaches the material hardness under sufficient contact, although strictly speaking, there exists a small increasing tendency of $p_{\mathrm{m}}$ owing to interactions of neighboring asperities, in line with the findings in Refs. [38, 41, 52, 72]. Many models of plastic contact of a rough surface assume that $p_{\mathrm{m}}$ corresponds to the material hardness, $H$, which is proportional to the yield stress [75]. Contact mechanics predicts $p_{m} / \sigma_{\mathrm{y}} \approx 3$ for a simple isolated asperity [76]. However, neighboring asperities can decrease the deviatoric components of the stress tensor, and tend to increase $p_{m} / \sigma_{\mathrm{y}}$; thus, the interactions between neighboring asperities allow $p_{\mathrm{m}}>3 \sigma_{\mathrm{y}}$ [36]. Our results suggest that, under well developed plastic deformation, the hardness or mean contact pressure of a strain hardening material is better for associating with a characteristic stress, which is a function of the yield stress and a characteristic strain, and thus $H=p_{\mathrm{m}} \approx 3 \sigma_{\mathrm{r}}$.

The unloading $A$ versus $p_{\mathrm{m}}$ curves for different materials can also be expressed through asigmoid logistic type function (see Figs. 5(b)-5(e)):

$$
\left(\frac{A}{A_{0}}\right)_{\max }-\frac{A}{A_{0}}=\frac{a_{1}}{1+a_{2} \exp \left\{-a_{3}\left[\left(\frac{p_{\mathrm{m}}}{\sigma_{r}}\right)_{\max }-\left(\frac{p_{\mathrm{m}}}{\sigma_{r}}\right)\right]\right\}}
$$

where $a_{2}$ and $a_{3}$ are dependent on the material properties, but independent of $A_{\max } / A_{0}$. The value of $a_{1}$ is directly related to the contact area, and $a_{1}=$ $100\left(A / A_{0}\right)$ (see Fig. 5(f)); in addition, note that the unit of measurement for a dimensionless contact area $A / A_{0}$ is the percentage (\%). At the initial stage of unloading, the contact area remains unvaried, although the mean contact pressure continues decreasing while unloading.

\subsection{Relation between contact area and load}

Both the area and geometry of the contact regions affect the interfacial stiffness and area-dependent properties (e.g., adhesion, contact stiffness, and electrical and thermal conductivity [36, 75, 77]). The contact area topology at different loading steps is displayed in Fig. 6, which shows the expansion of the equivalent plastic strain on the contact surface of Au-1 with increasing indentation displacement. Plastic deformation is an important factor in predicting the generation of debris caused by residual stress and micro-cracking [66]. As expected, the contact occurs at a finite number of discrete and isolated spots, leading to a complex contact morphology [36] because the entire contact region is composed of many tiny 

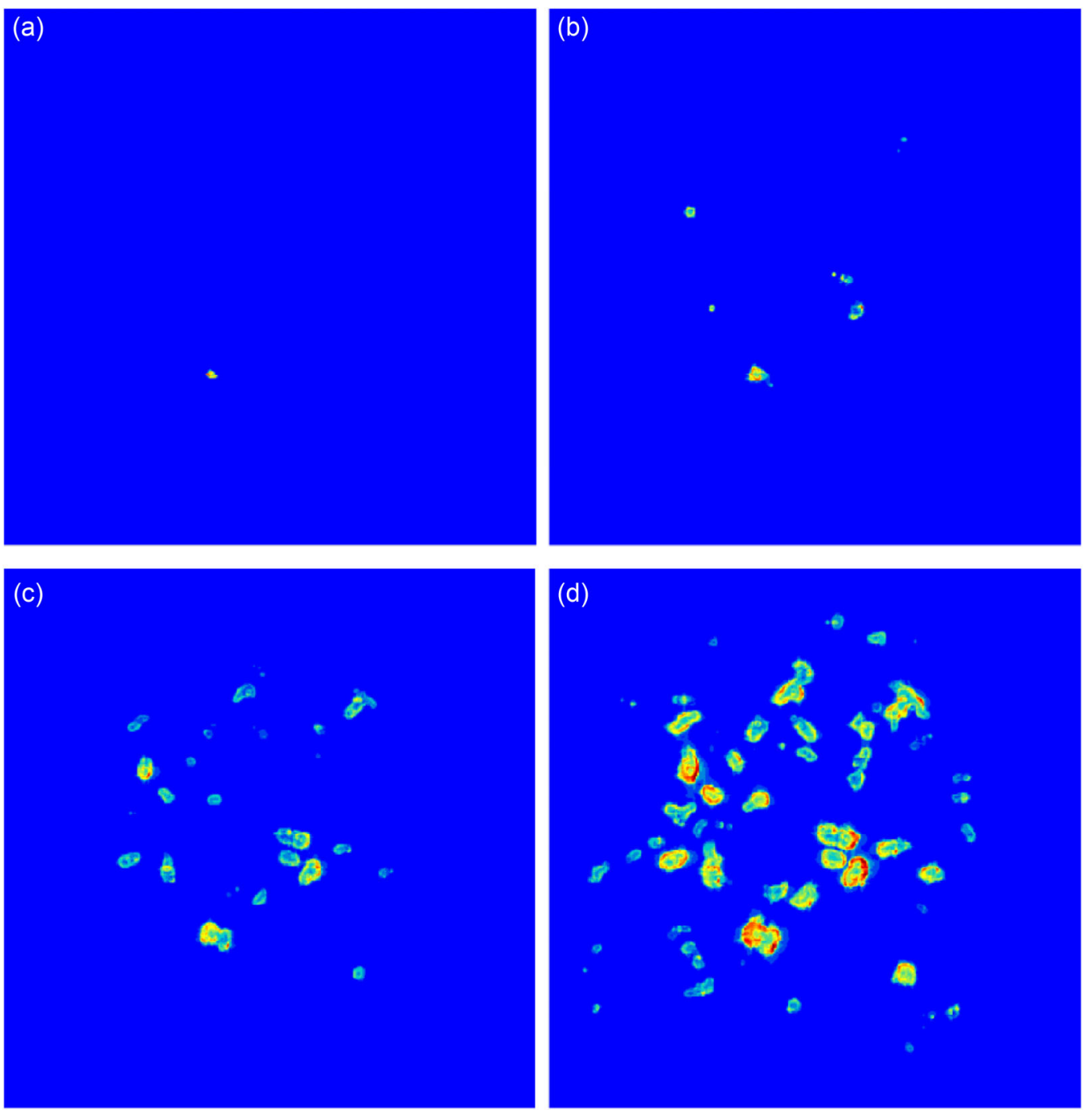

Fig. 6 Evolution of equivalent plastic strain field on the top surface $(2.5 \mu \mathrm{m} \times 2.5 \mu \mathrm{m})$ for different indentation displacements (material, Au-1): (a) $1.5 \mathrm{~nm}$; (b) $5.5 \mathrm{~nm}$; (c) $10.5 \mathrm{~nm}$; and (d) $16.5 \mathrm{~nm}$.

discrete regions [73]; the asperities experience plastic deformation as soon as contact occurs [41], demonstrating the invalidity of an elastic model in a real application because plastic deformation occurs even at an indentation displacement of as small as $1 \mathrm{~nm}$ owing to the fine roughness. Experiments showed that the interference under a fully plastic contact state is much smaller than the characteristic size (e.g., about $0.1 \%$ of the radius of the ball for contact between a rigid ball and a deformable space) [78], which is very difficult, if not impossible, to detect. As expected, because the rms slope $\left\langle|\partial z / \partial x|^{2}\right\rangle^{0.5}=0.94$ is much larger than $\sigma_{\mathrm{y}} / E_{\mathrm{r}}$ (where $E_{\mathrm{r}}=1 /\left(1-v^{2}\right)$. is the reduced elastic modulus), plastic deformation is induced at very small loads as soon as peaks of the asperities touch the indenter [36]. Neither the first contact nor the maximum contact pressure occurs at the surface center of the indented sample owing to the surface roughness.

Figure 7(a) shows a variation in the true contact area $A$ with indentation load $F$ during loading. Here, $F$ is normalized by $A_{0} \sigma_{\mathrm{r}}$. The contact area is proportional to the contact load, which is in line with previous studies [31, 32, 36-38, 72, 73, 79-81], because the area increases with the load to maintain a nearly constant contact pressure. For a rigid-perfectly plastic material, the real contact area is proportional to the load because the mean contact pressure is constant and equals the flow stress [72]. Similarly, for a strain hardening material, the mean contact pressure is also constant, and is equal to the characteristic stress. The 

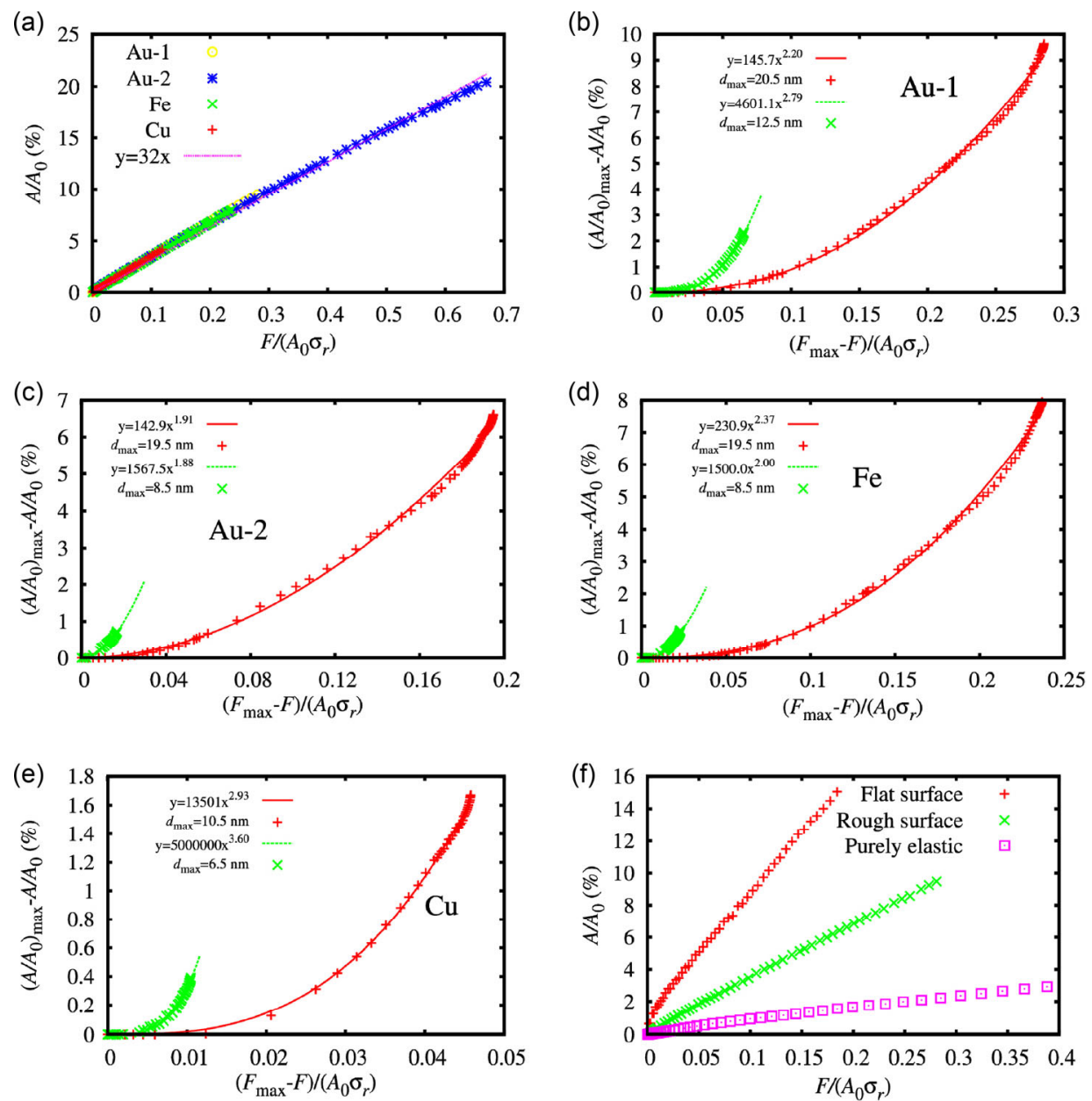

Fig. 7 Dependence of $A$ on $F$ : (a) loading and (b) unloading for Au-1; (c) unloading for Au-2; (d) unloading for Fe; (e) unloading for $\mathrm{Cu}$; and (f) loading under different conditions for $\mathrm{Au}-1$.

ratio of the load to the projected area is $0.92 \mathrm{GPa}$ for gold thin films under a spherical indentation [42], which is close to $H(\approx 1.3 \mathrm{GPa})$ for Au- 1 . It can be approximated that $F / A \approx 3 \sigma_{\mathrm{r}}$ for the loading, and the effect of the plastic constitutive law on the relation between the contact area and normal load during loading is based on the characteristic stress $\sigma_{\mathrm{r}}$.

The real contact area is a highly significant quantity because it dominates the creep curve of a rough surface [82], controls the electrical contact resistance [41], and provides insight into the adhesion-induced pull-off force [83]. The friction from adhesion is proportional to the real contact area $A$, and the formation probability of a wear particle increases with an increase in the real contact area [84]. It is well known that the frictional force, $T$, is proportional to a normal load, $F$, when sliding between a pair of contacting bodies occurs. The proportionality between $F$ and $A$ for the contact of rough surfaces is consistent with $T \propto F$. If the contact load is proportional to the contact area, a calibration of the area function of the indenter prior to the indentation test is unnecessary, provided that the proportionality, $H=F / A$, is known because the load can be known directly during the experiment. In addition, the contact area during loading can be calculated using $A=F / H$.

The unloading $A$ versus $F$ curves for different materials can be fitted using a power function (see Figs. 7(b)-7(e)),

$$
\left(\frac{A}{A_{0}}\right)_{\max }-\frac{A}{A_{0}}=D_{6}\left(\frac{F_{\max }-F}{A_{0} \sigma_{\mathrm{r}}}\right)^{D_{7}}
$$

where $D_{6}$ and $D_{7}$ are dependent on the material properties and the maximum indentation variables. The non-linearity of the unloading F-A curves manifests 
the irreversibility of plastic deformation.

Figure $7(\mathrm{f})$ compares $A$ versus $F$ curves under different conditions: a flat surface, rough surface, and purely elastic material (the reference material is $\mathrm{Au}-1$ ). Under a shallow indentation, a proportional relationship between the load and contact area also exists for a purely elastic solid. Under the same load, a purely elastic material underestimates the contact area, whereas a perfectly flat surface overestimates the contact area, because the contact stiffness for an elastic material is the largest, and for a flat surface is the smallest. A purely elastic material can sustain larger contact pressures than an elastic-plastic material, and therefore the same load requires a smaller contact area for an elastic material. A reduced contact area and higher mean contact pressure for a purely elastic solid was also found in [38], which describes an effective way to modify the surface roughness to adjust the sur-
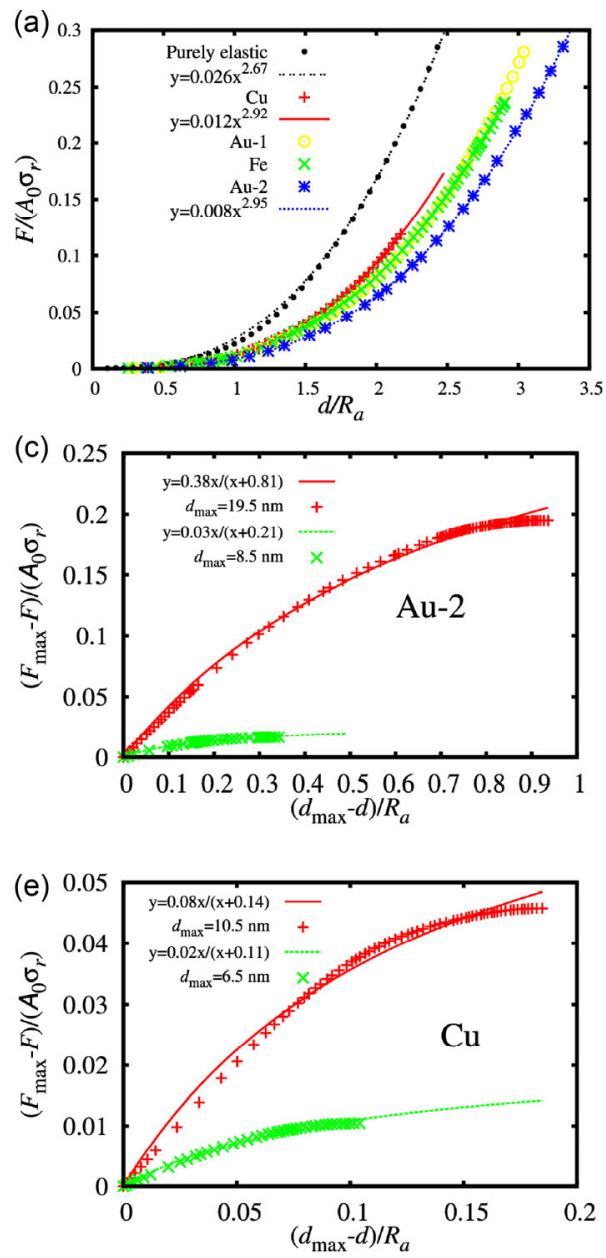

face stiffness. The mean contact pressure is dependent on both the material and roughness because $p_{\mathrm{m}} / \sigma_{\mathrm{r}} \approx$ $12.6\left(p_{\mathrm{m}} / E=0.1\right)$ for a purely elastic material, $p_{\mathrm{m}} / \sigma_{\mathrm{r}} \approx 2.9$ for a rough surface, and $p_{\mathrm{m}} / \sigma_{\mathrm{r}} \approx 1.16$ for a flat surface. Even for contact of an isolated asperity, $p_{\mathrm{m}} / \sigma_{\mathrm{y}}$ is not a constant but is dependent on the material properties and geometrical parameters [85]. For a spherical indentation of a flat surface, when a plastic deformation is initiated, Hertz theory predicts that $p_{\mathrm{m}} / \sigma_{\mathrm{y}} \approx 1.07$ [76], which is close to the value of $p_{\mathrm{m}} / \sigma_{\mathrm{r}} \approx 1.16$ for a spherical indentation of a linear hardening material, and indicates the role of characteristic stress in the contact of a strain hardening material.

\subsection{Indentation load-displacement curves}

Figure 8(a) shows the load-displacement curves for different materials during loading. The reference material for the purely elastic case is $\mathrm{Au}-1$. A power
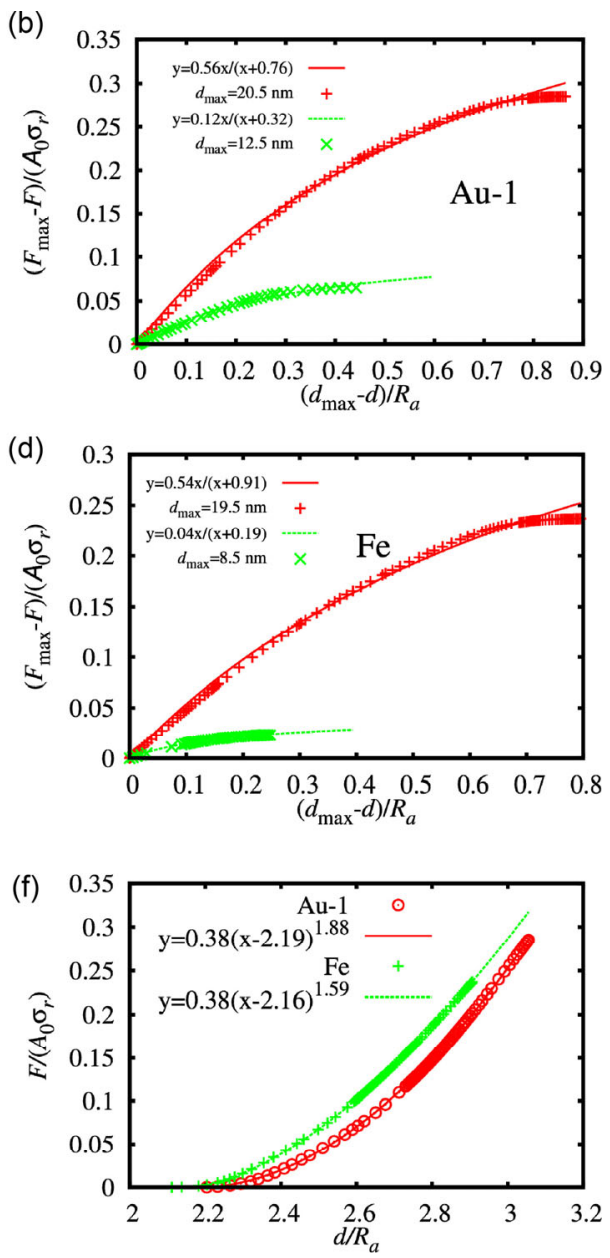

Fig. 8 Indentation load-displacement curves: (a) loading and (b) unloading for Au-1; (c) unloading for Au-2; (d) unloading for Fe; (e) unloading for $\mathrm{Cu}$; and (f) loading with another fitting function. 
function can be used for the $F-d$ relation during loading for both purely elastic and elastic-plastic solids:

$$
\frac{F}{A_{0} \sigma_{\mathrm{r}}}=D_{8}\left(\frac{d}{R_{a}}\right)^{D_{9}}
$$

For elastic contact of two nominally flat rough surfaces, the contact stiffness (i.e., the slope of the $F-d$ curve during loading) increases proportionally with the normal load $F$ [46], suggesting a power-law relationship [86], although this has yet to be confirmed [87]. A power-law relation exists between the contact stiffness and $F$ for contact between a nominally flat surface and a sphere during loading, demonstrating the critical role of the contact geometry.

The unloading indentation load-displacement curves can be fitted using a plateau curve (see Figs. 8(b)-8(e)),

$$
F_{\max }-F=D_{10}\left(d_{\max }-d\right)^{D_{11}}
$$
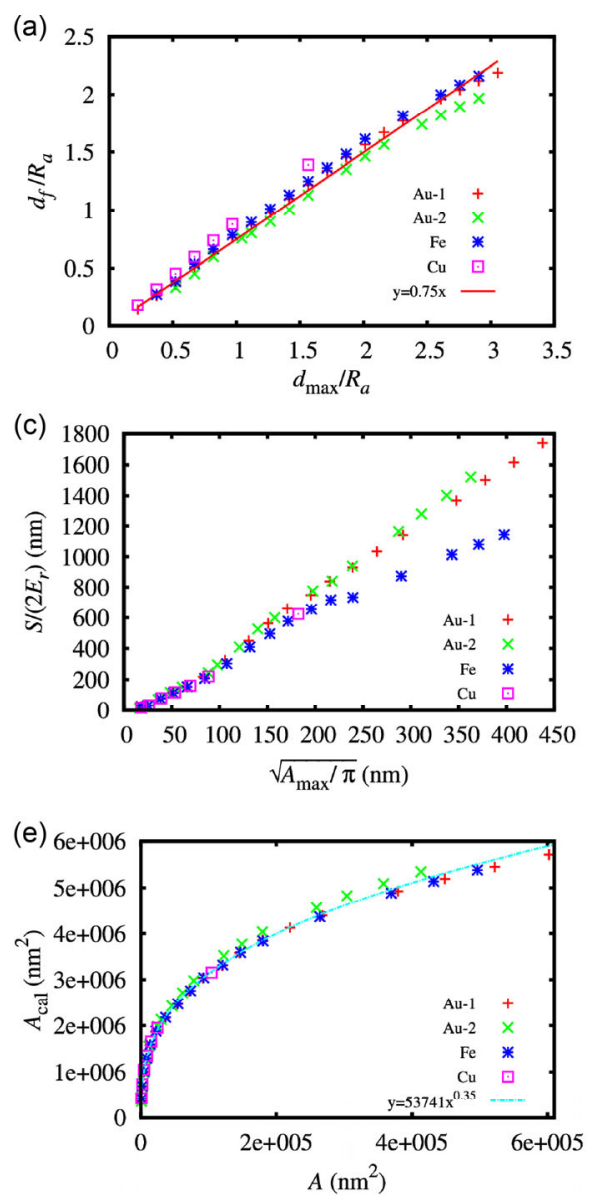

where parameters $D_{10}$ and $D_{11}$ depend on both the material properties and the maximum loading variables. Another power-law function [88] can also be used for the unloading curves (see Fig. 8(f)):

$$
F=D_{12}\left(d-d_{\mathrm{f}}\right)^{D_{13}}
$$

where subscript " $\mathrm{f}$ " denotes the value upon final unloading. The exponent $D_{13}$ is distinctly larger than 1 , implying a nonlinear unloading behavior different from that of a flat punch. It was found that $d_{\mathrm{f}} / d_{\max } \approx$ 0.75 is in line with the contact deformation of an isolated asperity [85], and exponent $D_{13}$ is within the range of 1.6 and 2.3, which is larger than the normal value [89].

\subsection{Calculated variables}

The residual displacement was found to be proportional to the maximum displacement, and $d_{\mathrm{f}} / d_{\max } \approx$ 0.75 (see Fig. 9(a)). The plastic energy dissipated (i.e.,
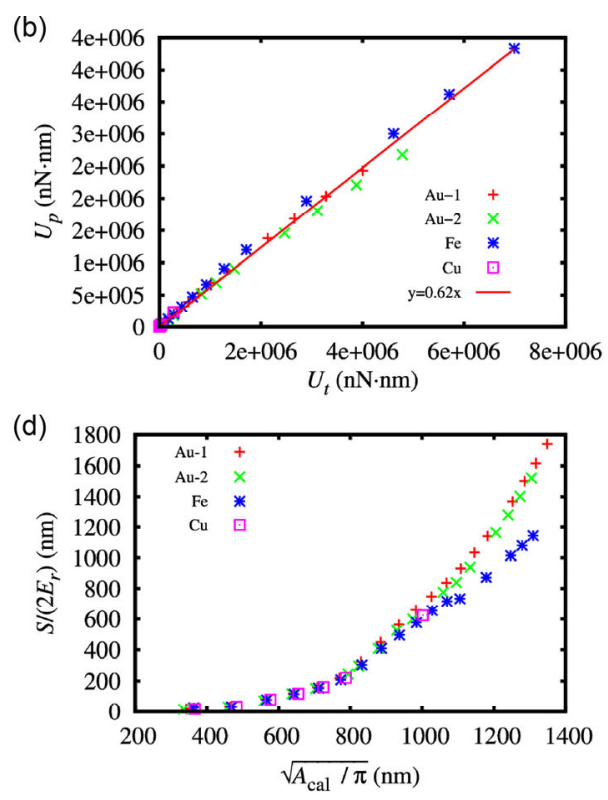

Fig. 9 Calculated variables: (a) residual displacement; (b) plastic dissipation; (c) $S$ vs. $A$; (d) $S$ vs. $A_{\text {cal }}$; and (e) relation between real and calculated contact areas. 
the area under one loading/unloading $F$ - $d$ cycle), $U_{\mathrm{p}}$ was found to be proportional to the work done (i.e., the area under only the loading part of the $F-d$ curve), $U_{\mathrm{t}}$ during loading, and $U_{\mathrm{p}} / U_{\mathrm{t}} \approx 0.62$ (see Fig. 9(b)). As expected, the maximum displacement has little effect on the dimensionless key variables (i.e., $d_{\mathrm{f}} / d_{\max }$ and $\left.U_{\mathrm{p}} / U_{\mathrm{t}}\right)$ during unloading $[85,90]$, namely, $U_{\mathrm{p}} / U_{\mathrm{t}}$ is the elastic-plastic-loading or plasticity index, $U_{\mathrm{p}} / U_{\mathrm{t}}=1$ for a fully plastic contact [90], and $U_{\mathrm{p}} / U_{\mathrm{t}}$ is equivalent to $d_{\mathrm{f}} / d_{\max }$ for both a spherical contact [55] and a sinusoidal contact [85]. For contact of a rough surface, a close relation also exists between $d_{\mathrm{f}} / d_{\max }$ and $U_{\mathrm{p}} / U_{\mathrm{t}}$, and the values are more dependent on the geometrical parameters than the material properties. Therefore, $d_{\mathrm{f}} / d_{\max }$ and $U_{\mathrm{p}} / U_{\mathrm{t}}$, from indentation tests can be used to calibrate the surface topography, as proposed by [36].

For a smooth indented surface, the slope $S$ of $F$ versus the $d$ curve at the initial unloading is related to the effective modulus, $E_{\text {eff }}$ as in Refs. [81, 89, 91]:

$$
E_{\text {eff }}=\frac{S / 2}{\sqrt{A_{\max } / \pi}}
$$

where $S$ can be calculated using the Oliver and Pharr power-law function as

$$
S=D_{12} D_{13}\left(d_{\max }-d_{\mathrm{f}}\right)^{\left(D_{13}-1\right)}
$$

As expected, a proportional relationship exists between contact stiffness $S$ and the square root of the contact area (see Fig. 9(c)). Although, the calculated effective elastic modulus $E_{\text {eff }}$ is larger than the input value $E_{\mathrm{r}}$ used in the simulation, under a shallow indentation (i.e., a small $A$ ), the calculated $E_{\text {eff }}$ from Eq. (12) is proportional to the input values $E_{\mathrm{r}}\left(E_{\mathrm{eff}} \approx\right.$ $3.3 E_{\mathrm{r}}$ ); under a large contact area, the relation between $E_{\text {eff }}$ and $E_{\mathrm{r}}$ is dependent on the specific strain-hardening rule.

If a circular contact region is assumed for contact between a smooth sphere and a rough flat surface [92], the contact area can be approximated as [89]

$$
A_{\text {cal }}=\pi\left(2 R-h_{\mathrm{c}}\right) h_{\mathrm{c}}
$$

where $R$ is the radius of the spherical indenter, and

$$
h_{\mathrm{c}}=h_{\max }-0.75 \frac{F_{\max }}{S}
$$

Figure 9(d) shows similar results as Fig. 9(c), except that the calculated $A_{\text {cal }}$ is used instead of the measured $A$. Under a shallow indentation, the relation between normal contact stiffness $S$ and the calculated contact area $A_{\text {cal }}$ is independent of the material, whereas the relation is affected by the strain hardening law under a large indentation. Although the magnitude of the effective elastic modulus calculated from a shallow indentation test is larger than the real value, the results from a shallow indentation can be used for a relative comparison. Under a large indentation, the strain hardening law has a prominent effect on the calculated elastic modulus.

Figure 9(e) compares the measured $A$ and calculated $A_{\text {cal. }}$. The real contact area for a rough surface is smaller than that calculated when assuming a circular contact. The assumptions (e.g., a circular contact region, and the maximum contact pressure at the center of the surface for contact between a smooth sphere and a rough flat surface) used in theoretical models of the contact of a rough surface [92] should be improved for consistency between the calculated and real contact areas.

\section{Conclusion}

Contact between a rigid sphere and a nominally flat rough surface was studied using the finite element method while considering different strain-hardening rules. The surface roughness, measured experimentally using AFM, was applied to generate a 3D FE mesh. Contact variables such as the indentation load, displacement, contact area, and mean contact pressure were obtained for both loading and unloading, and their relations were quantified using a curve fitting of the power law and sigmoid logistic types. The characteristic stress, which depends on both the material properties and the contact geometries, was found to be associated with the mean contact pressure. The deterministic finite element modeling shows a proportional relation between the contact area and load. The surface roughness makes the effective elastic modulus calculated from the initial unloading loaddisplacement curve several times larger than the material value for a shallow indentation. The effects of the wavelengths on the surface profiles with various 
degrees of surface roughness and surface measurement parameters (e.g., AFM scan resolution and range) will be studied in a future work. The calculated results under a small contact area can only serve as a relative comparison. The normalized contact responses (e.g., contact area and load) are material dependent. The ratios of residual displacement over the maximum displacement, and the plastic energy dissipated after the final unloading over the work applied after loading, were found to be independent of the material properties. The dependence of these ratios on the surface roughness will be studied as a future work.

\section{Acknowledgements}

This project is supported by National Natural Science Foundation of China (Grant Nos. 51705082, 51875016), Fujian Provincial Minjiang Scholar (No. 0020-510486), and Fujian Provincial Collaborative Innovation Center for High-end Equipment Manufacturing (No. 002050006103).

Open Access: The articles published in this journal are distributed under the terms of the Creative Commons Attribution 4.0 International License (http://creativecommons.org/licenses/by/4.0/), which permits unrestricted use, distribution, and reproduction in any medium, provided you give appropriate credit to the original author(s) and the source, provide a link to the Creative Commons license, and indicate if changes were made.

\section{References}

[1] Zhang S J, To S, Wang S J, Zhu Z W. A review of surface roughness generation in ultra-precision machining. Int J Mach Tools Manuf 91: 76-95 (2015)

[2] Gupta M K, Sood P K. Surface roughness measurements in NFMQL assisted turning of titanium alloys: An optimization approach. Friction 5(2): 155-170 (2017)

[3] Murashov M V, Panin S D. Numerical modelling of contact heat transfer problem with work hardened rough surfaces. Int J Heat Mass Transfer 90: 72-80 (2015)

[4] Ghosh A, Sadeghi F. A novel approach to model effects of surface roughness parameters on wear. Wear 338-339: 73-94 (2015)
[5] Wang Y C, Liu Y, Wang Z C, Wang Y M. Surface roughness characteristics effects on fluid load capability of tilt pad thrust bearings with water lubrication. Friction 5(4): 392-401 (2017)

[6] Petean P G C, Aguiar M L. Determining the adhesion force between particles and rough surfaces. Powder Technol 274: 67-76 (2015)

[7] Svetovoy V B, Palasantzas G. Influence of surface roughness on dispersion forces. Adv Colloid Interface Sci 216: 1-19 (2015)

[8] Lyon K, Zhang Y Y, Mišković Z L, Song Y H, Wang Y N. Interaction of fast charges with a rough metal surface. Surf Sci 639: 32-38 (2015)

[9] Liu Q F, Wang L, Shen S P. Effect of surface roughness on elastic limit of silicon nanowires. Comput Mater Sci 101: 267-274 (2015)

[10] Nunez E E, Polycarpou A A. The effect of surface roughness on the transfer of polymer films under unlubricated testing conditions. Wear 326-327: 74-83 (2015)

[11] Zhu Y, Chen X, Wang W, Yang H. A study on iron oxides and surface roughness in dry and wet wheel-rail contacts. Wear 328-329: 241-248 (2015)

[12] Dawood H I, Mohammed K S, Rahmat A, Uday M B. The influence of the surface roughness on the microstructures and mechanical properties of 6061 aluminium alloy using friction stir welding. Surf Coat Technol 270: 272-283 (2015)

[13] Curry N, Tang Z L, Markocsan N, Nylén P. Influence of bond coat surface roughness on the structure of axial suspension plasma spray thermal barrier coatings-Thermal and lifetime performance. Surf Coat Technol 268: 15-23 (2015)

[14] Wang S. Real contact area of fractal-regular surfaces and its implications in the law of friction. $J$ Tribol 126(1): 1-8 (2004)

[15] Wang S, Shen J, Chan W K. Determination of the fractal scaling parameter from simulated fractal-regular surface profiles based on the weierstrass-mandelbrot function. $J$ Tribol 129(4): 952-956 (2007)

[16] Wang S, Komvopoulos K. A fractal theory of the interfacial temperature distribution in the slow sliding regime: Part IIMultiple domains, elastoplastic contacts and applications. J Tribol 116(4): 824-832 (1994)

[17] Yan W, Komvopoulos K. Contact analysis of elastic-plastic fractal surfaces. $J$ Appl Phys 84(7): 3617-3624 (1998)

[18] Komvopoulos K, Gong Z Q. Stress analysis of a layered elastic solid in contact with a rough surface exhibiting fractal behavior. Int J Solids Struct 44(7-8): 2109-2129 (2007)

[19] Gao Y F, Bower A F, Kim K S, Lev L, Cheng Y T. The behavior of an elastic-perfectly plastic sinusoidal surface under contact loading. Wear 261(2): 145-154 (2006) 
[20] Bemporad A, Paggi M. Optimization algorithms for the solution of the frictionless normal contact between rough surfaces. Int J Solids Struct 69-70: 94-105 (2015)

[21] Xu Y, Jackson R L, Marghitu D B. Statistical model of nearly complete elastic rough surface contact Int $J$ Solids Struct 51(5): 1075-1088 (2014)

[22] Yastrebov V A, Anciaux G, Molinari J F. From infinitesimal to full contact between rough surfaces: Evolution of the contact area. Int J Solids Struct 52: 83-102 (2015)

[23] Greenwood J A. On the almost-complete contact of elastic rough surfaces: The removal of tensile patches. Int $J$ Solids Struct 56-57: 258-264 (2015)

[24] Berthe L, Sainsot P, Lubrecht A A, Baietto M C. Plastic deformation of rough rolling contact: An experimental and numerical investigation. Wear 312(1-2): 51-57 (2014)

[25] Raffa M L, Lebon F, Vairo G. Normal and tangential stiffnesses of rough surfaces in contact via an imperfect interface model. Int J Solids Struct 87: 245-253 (2016)

[26] Kogut L, Komvopoulos K. Analysis of the spherical indentation cycle for elastic-perfectly plastic solids. J Mater Res 19(12): 3641-3653 (2004)

[27] Xu H, Komvopoulos K. Surface adhesion and hardening effects on elastic-plastic deformation, shakedown and ratcheting behavior of half-spaces subjected to repeated sliding contact. Int J Solids Struct 50(6): 876-886 (2013)

[28] Song Z, Komvopoulos K. Elastic-plastic spherical indentation: Deformation regimes, evolution of plasticity, and hardening effect. Mech Mater 61: 91-100 (2013)

[29] Greenwood J A, Williamson J B P. Contact of nominally flat surfaces. Proc Roy Soc A 295(1442): 300-319 (1966)

[30] Hertz H. Ueber die berührung fester elastischer körper. J Reine Angew Math 1882(92): 156-171 (1882)

[31] Bush A W, Gibson R D, Thomas T R. The elastic contact of a rough surface. Wear 35(1): 87-111 (1975)

[32] Persson B N J. Elastoplastic contact between randomly rough surfaces. Phys Rev Lett 87(11): 116101 (2001)

[33] Chang W R, Etsion I, Bogy D B. An elastic-plastic model for the contact of rough surfaces. J Tribol 109(2): 257-263 (1987)

[34] Chang W R. An elastic-plastic contact model for a rough surface with an ion-plated soft metallic coating. Wear 212(2): 229-237 (1997)

[35] Zhao Y W, Maietta D M, Chang L. An asperity microcontact model incorporating the transition from elastic deformation to fully plastic flow. J Tribol 122(1): 86-93 (1999)

[36] Pei L, Hyun S, Molinari J F, Robbins M O. Finite element modeling of elasto-plastic contact between rough surfaces. J Mech Phys Solids 53(11): 2385-2409 (2005)
[37] Hyun S, Pei L, Molinari J F, Robbins M O. Finite-element analysis of contact between elastic self-affine surfaces. Phys Rev E 70(2): 026117 (2004)

[38] Poulios K, Klit P. Implementation and applications of a finite-element model for the contact between rough surfaces. Wear 303(1-2): 1-8 (2013)

[39] Dong Q, Cao J G. Contact deformation analysis of elasticplastic asperity on rough roll surface in a strip steel mill. $J$ Fail Anal Prev 15(2): 320-326 (2015)

[40] Liu Z Q, Shi J P, Wang F S, Yue Z F. Normal contact stiffness of the elliptic area between two asperities. Acta Mech Solida Sin 28(1): 33-39 (2015)

[41] Liu H, Leray D, Colin S, Pons P, Broué A. Finite element based surface roughness study for ohmic contact of microswitches. In Proceedings of 2012 IEEE 58th Holm Conference on Electrical Contacts, Portland, OR, USA, 2012: 1-10.

[42] Arrazat B, Mandrillon V, Inal K, Vincent M, Poulain C. Microstructure evolution of gold thin films under spherical indentation for micro switch contact applications. $J$ Mater Sci 46(18): 6111 (2011)

[43] Krim I, Palasantzas G. Experimental observations of self-affine scaling and kinetic roughening at sub-micron lengthscales. Int J Mod Phys B 9(6): 599-632 (1995)

[44] Bouchaud E. Scaling properties of cracks. J Phys Condens Matter 9: 4319-4344 (1997)

[45] Meakin P. Fractals, Scaling and Growth Far from Equilibrium. Cambridge (UK): Cambridge University Press, 1998.

[46] Buczkowski R, Kleiber M, Starzyński G. Normal contact stiffness of fractal rough surfaces. Arch Mech 66(6): 411428 (2014)

[47] Farhat C, Roux F X. Implicit parallel processing in structural mechanics. Comput Mech Adv 2: 1-124 (1994)

[48] Yastrebov V A, Durand J, Proudhon H, Cailletaud G. Rough surface contact analysis by means of the Finite Element Method and of a new reduced model. Compt Rend Mécan 339(7-8): 473-490 (2011)

[49] Liu M, Proudhon H. Finite element analysis of contact deformation regimes of an elastic-power plastic hardening sinusoidal asperity. Mech Mater 103: 78-86 (2016)

[50] Hughes T J R. The Finite Element Method: Linear Static and Dynamic Finite Element Analysis. Mineola, (NY): PrenticeHall, 2000.

[51] Mesarovic S D, Fleck N A. Frictionless indentation of dissimilar elastic-plastic spheres. Int J Solids Struct 37(46-47): 7071-7091 (2000)

[52] Kral E R, Komvopoulos K, Bogy D B. Elastic-plastic finite element analysis of repeated indentation of a half-space by a rigid sphere. $J$ Appl Mech 60(4): 829-841 (1993) 
[53] Yang F, Kao I. Interior stress for axisymmetric abrasive indentation in the free abrasive machining process: Slicing silicon wafers with modern wiresaw. J Electron Packag 121(3): 191-195 (1999)

[54] Mata M, Anglada M, Alcalá J. Contact deformation regimes around sharp indentations and the concept of the characteristic strain. J Mater Res 17(5): 964-976 (2002)

[55] Etsion I, Kligerman Y, Kadin Y. Unloading of an elasticplastic loaded spherical contact. Int J Solids Struct 42(13): 3716-3729 (2005)

[56] Sahoo P, Chatterjee B, Adhikary D. Finite element based elastic-plastic contact behaviour of a sphere against a rigid flat-Effect of strain hardening. Int J Eng Technol 2(1): 1-6 (2010)

[57] Chen W M, Li M, Cheng Y T. Analysis on elastic-plastic spherical contact and its deformation regimes, the one parameter regime and two parameter regime, by finite element simulation. Vacuum 85(9): 898-903 (2011)

[58] Celentano D J, Guelorget B, François M, Cruchaga M A, Slimane A. Numerical simulation and experimental validation of the microindentation test applied to bulk elastoplastic materials. Model Simul Mat Sci Eng 20(4): 045007 (2012)

[59] Mata M, Alcalá J. The role of friction on sharp indentation. J Mech Phys Solids 52(1): 145-165 (2004)

[60] Brizmer V, Kligerman Y, Etsion I. The effect of contact conditions and material properties on the elasticity terminus of a spherical contact. Int J Solids Struct 43(18-19): 57365749 (2006)

[61] Zait Y, Kligerman Y, Etsion I. Unloading of an elasticplastic spherical contact under stick contact condition. Int J Solids Struct 47(7-8): 990-997 (2010)

[62] Liu M, Proudhon H. Finite element analysis of frictionless contact between a sinusoidal asperity and a rigid plane: Elastic and initially plastic deformations. Mech Mater 77: 125-141 (2014)

[63] Chatterjee B, Sahoo P. Finite-element-based multiple normal loading-unloading of an elastic-plastic spherical stick contact. ISRN Tribol 2013: 871634 (2013)

[64] Chatterjee B, Sahoo P. Effect of strain hardening on unloading of a deformable sphere loaded against a rigid flat-A finite element study. Int J Eng Technol 2(4): 225-233 (2010)

[65] Du Y, Chen L, McGruer N E, Adams G G, Etsion I. A finite element model of loading and unloading of an asperity contact with adhesion and plasticity. $J$ Colloid Interface Sci 312(2): 522-528 (2007)

[66] Peng W, Bhushan B. Three-dimensional contact analysis of layered elastic/plastic solids with rough surfaces. Wear 249(9): 741-760 (2001)
[67] Carmichael C. Kent's Mechanical Engineers' Handbook in Two Volumes. 12th ed. New York (USA): John Wiley \& Sons, 1950.

[68] Galambos T V. Guide to Stability Design Criteria for Metal Structures. 5th ed. New York (USA): Wiley, 1998.

[69] Brizmer V, Zait Y, Kligerman Y, Etsion I. The effect of contact conditions and material properties on elastic-plastic spherical contact. J Mech Mater Struct 1(5): 865-879 (2006)

[70] Kogut L, Etsion I. Elastic-plastic contact analysis of a sphere and a rigid flat. $J$ Appl Mech 69(5): 657-662 (2002)

[71] Gadelrab K R, Chiesa M. Numerically assisted nanoindentation analysis. Mater Sci Eng A 560: 267-272 (2013)

[72] Kucharski S, Klimczak T, Polijaniuk A, Kaczmarek J. Finiteelements model for the contact of rough surfaces. Wear 177(1): 1-13 (1994)

[73] Wang F S, Block J M, Chen W W, Martini A, Zhou K, Keer L M, Wang Q J. A multilevel model for elastic-plastic contact between a sphere and a flat rough surface. J Tribol 131(2): 021409 (2009)

[74] Li L, Etsion I, Talke F E. Elastic-plastic spherical contact modeling including roughness effects. Tribol Lett 40(3): 357-363 (2010)

[75] Bowden F P, Tabor D, Palmer F. The Friction and Lubrication of Solids. Oxford (UK): Clarendon Press 1954.

[76] Johnson K L, Reviewer L M K. Contact mechanics. J Tribol 108(4): 659 (1986)

[77] Berthoud P, Baumberger T. Shear stiffness of a solid-solid multicontact interface. Proc Royal Soc A 454(1974): 16151634 (1998)

[78] Shankar S, Mayuram M M. Effect of strain hardening in elastic-plastic transition behavior in a hemisphere in contact with a rigid flat. Int J Solids Struct 45(10): 3009-3020 (2008)

[79] Archard J F. Elastic deformation and the laws of friction. Proc Royal Soc A 243(1233) 190-205 (1957)

[80] Levinson O, Etsion I, Halperin G. An experimental investigation of elastic plastic contact and friction of a sphere on flat. In STLE/ASME 2003 International Joint Tribology Conference, Ponte Vedra Beach, Florida, USA, 2003.

[81] Buczkowski R, Kleiber M. Elasto-plastic statistical model of strongly anisotropic rough surfaces for finite element 3Dcontact analysis. Comput Methods Appl Mech Eng 195(37-40): 5141-5161 (2006)

[82] Bucher F, Knothe K, Theiler A. Normal and tangential contact problem of surfaces with measured roughness. Wear 253(1-2): 204-218 (2002)

[83] Eid H, Adams G G, McGruer N E, Fortini A, Buldyrev S, Srolovitz D. A combined molecular dynamics and finite element analysis of contact and adhesion of a rough sphere and a flat surface. Tribol Transs 54(6): 920-928 (2011) 
[84] Bhushan B. Principles and applications of tribology. Ind Lubr Tribol 51(6): 313 (1999)

[85] Liu M. Finite element analysis of large contact deformation of an elastic-plastic sinusoidal asperity and a rigid flat. Int J Solids Struct 51(21-22): 3642-3652 (2014)

[86] Pohrt R, Popov V L. Normal contact stiffness of elastic solids with fractal rough surfaces. Phys Rev Lett 108(10): 104301 (2012)

[87] Pastewka L, Prodanov N, Lorenz B, Müser M H, Robbins $\mathrm{M} \mathrm{O}$, Persson B N J. Finite-size scaling in the interfacial stiffness of rough elastic contacts. Phys Rev E 87(6): 062809 (2013)

[88] Sneddon I N. The relation between load and penetration

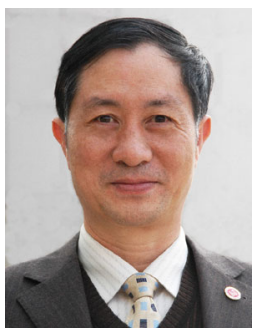

Chenghui GAO. He received his $\mathrm{PhD}$ in mechanical engineering from China Academy of Machinery Science \& Technology in 1990, and is the founder and the leader of the Research Institute of Tribology in Fuzhou University. He was vice-

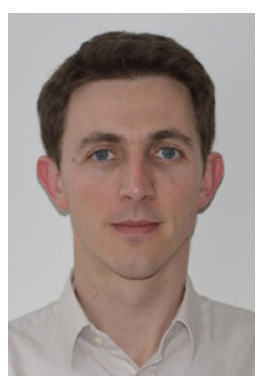

Henry PROUDHON. He received his $\mathrm{PhD}$ in engineering and science from Institut National des Sciences Appliquées de Lyonin 2005, and is now a CNRS research associate in Centre des Matériaux, MINES Paristech. Before joining the French National Centre for Scientific

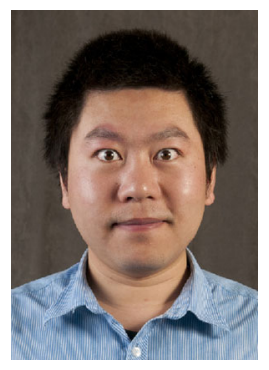

Ming LIU. He received his $\mathrm{PhD}$ in materials science and engineering from the University of Kentucky in 2012. He was a post-doctorate researcher at the Centre of Materials, Mines Paris Tech France in 2013, and at Washington State University in 2014. He joined the School of in the axisymmetric boussinesq problem for a punch of arbitrary profile. Int J Eng Sci 3(1): 47-57 (1965)

[89] Oliver W C, Pharr G M. An improved technique for determining hardness and elastic modulus using load and displacement sensing indentation experiments. $J$ Mater Res 7(6): 1564-1583 (1992)

[90] Kadin Y, Kligerman Y, Etsion I. Unloading an elasticplastic contact of rough surfaces. J Mech Phys Solids 54(12): 2652-2674 (2006)

[91] King R B. Elastic analysis of some punch problems for a layered medium. Int J Solids Struct 23(12): 1657-1664 (1987)

[92] Kagami J, Yamada K, Hatazawa T. Contact between a sphere and rough plates. Wear 87(1): 93-105 (1983)

president of Fuzhou University, and has received many awards such as National Model Teacher, "Ten Thousand People Plan" Outstanding Teacher of the Ministry of Education, Fujian Provincial Outstanding Teacher, and Fujian Provincial Second Prize of Science and Technology Progress.

Research, Centre des Matériaux P.M. Fourt, in 2007, he served as a post-doctoral researcher at the University of British Columbia and at Institut National des Sciences Appliquées de Lyon. He won a RIST medal from the French Metallurgy and Material Society SF2M in 2013. His research topics include elasticity and plasticity of crystalline solids, fretting fatigue damage mechanisms, and multi-scale contact mechanics.

Mechanical Engineering and Automation, Fuzhou University in 2015, and became a professor and doctor supervisor thanks to Fujian Provincial Minjiang Scholar Program. His research focus is on micro/nano mechanical testing, characterization of advanced materials, and computational modeling of multiple physics problems. 